UCRL-JC-130811 Rev 1

PREPRINT

\title{
Development of Integrated Mechanistically-Based Degradation-Mode Models for Performance Assessment of High -Level Waste Containers
}

\author{
J. C. Farmer \\ R. D. McCright \\ J. C. Estill \\ S. R. Gordon
}

This paper was prepared for submittal to the Fall Meeting of the Materials Research Society Boston, MA

Nov. 28-Dec.4, 1998

December 21, 1998

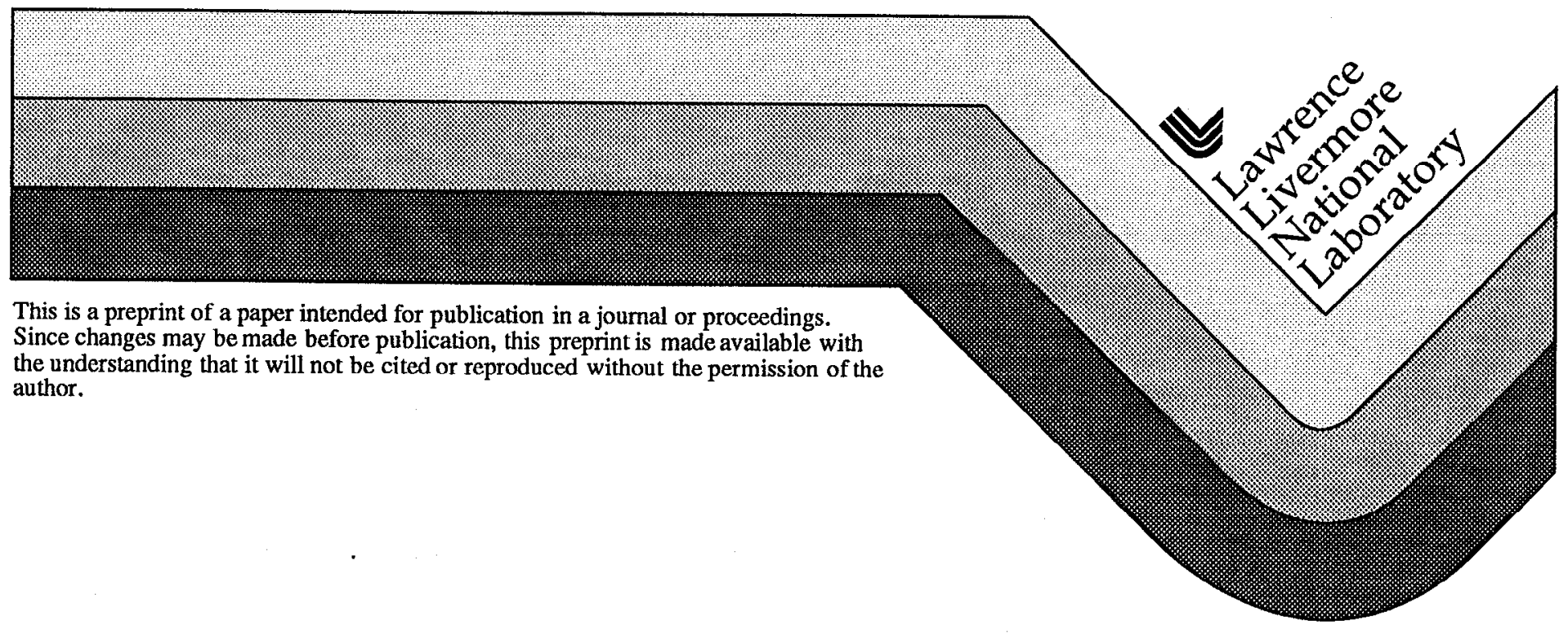




\section{DISCLAIMER}

This document was prepared as an account of work sponsored by an agency of the United States Government. Neither the United States Government nor the University of California nor any of their employees, makes any warranty, express or implied, or assumes any legal liability or responsibility for the accuracy, completeness, or usefulness of any information, apparatus, product, or process disclosed, or represents that its use would not infringe privately owned rights. Reference herein to any specific commercial product, process, or service by trade name, trademark, manufacturer, or otherwise, does not necessarily constitute or imply its endorsement, recommendation, or favoring by the United States Government or the University of California. The views and opinions of authors expressed herein do not necessarily state or reflect those of the United States Government or the University of California, and shall not be used for advertising or product endorsement purposes. 


\title{
DEVELOPMENT OF \\ INTEGRATED MECHANISTICALLY-BASED DEGRADATION-MODE MODELS FOR PERFORMANCE ASSESSMENT OF HIGH-LEVEL WASTE CONTAINERS
}

\author{
J. C. FARMER, R. D. MCCRIGHT, J. C. ESTILL \& S. R. GORDON \\ Lawrence Livermore National Laboratory \\ Livermore, California 94550
}

\begin{abstract}
Alloy 22 [UNS N06022] is now being considered for construction of high level waste containers to be emplaced at Yucca Mountain and elsewhere. In essence, this alloy is 20.0-22.5\% $\mathrm{Cr}, 12.5-14.5 \% \mathrm{Mo}, 2.0-6.0 \% \mathrm{Fe}, 2.5-3.5 \% \mathrm{~W}$, with the balance being Ni. Other impurity elements include $\mathrm{P}, \mathrm{Si}, \mathrm{S}, \mathrm{Mn}, \mathrm{Co}$ and V. Cobalt may be present at a maximum concentration of $2.5 \%$. Detailed mechanistic models have been developed to account for the corrosion of Alloy 22 surfaces in crevices that will inevitably form. Such occluded areas experience substantial decreases in $\mathrm{pH}$, with corresponding elevations in chloride concentration. Experimental work has been undertaken to validate the crevice corrosion model, including parallel studies with 304 stainless steel.
\end{abstract}

\section{BACKGROUND}

Initially, the high-level waste containers will be hot and dry due to the heat generated by radioactive decay. However, the temperature will eventually drop to levels where both humid air and aqueous phase corrosion will be possible. Crevices will be formed between waste package and supports; beneath mineral precipitates, corrosion products, dust, rocks, cement and biofilms, and between double-wall containers. It is well known that the crevice environment will be more severe than the near field environment (NFE). The hydrolysis of dissolved metal will lead to the accumulation of $\mathrm{H}^{+}$and the corresponding decrease of $\mathrm{pH}$. Field-driven electromigration of $\mathrm{Cl}^{-}$ (and other anions) into crevice must occur to balance cationic charge associated with $\mathrm{H}^{+}$ions [1-3]. The exacerbated conditions inside the crevice set the stage for subsequent attack of the corrosion resistant material (CRM) by passive corrosion, pitting (initiation \& propagation), stress corrosion cracking (initiation \& propagation), or other mechanisms. Clearly, the development of an adequate crevice corrosion model for determination of the exact nature of the local environment is prudent.

Alloy 22 has several desirable attributes that make it an attractive candidate for fabrication of high-level waste containers. It is less susceptible to localized corrosion (LC) in environments that contain $\mathrm{Cl}^{-}$than Alloys 825 and 625, that were leading candidates in earlier designs [4]. The unusual LC resistance of Alloy 22 is believed to be due to the additions of both Mo and W, which should stabilize the passive film at very low $\mathrm{pH}$ [5]. In regard to the addition of tungsten to Alloy 22, note that $\mathrm{WO}_{3}$ appears to be less soluble at low $\mathrm{pH}$ than $\mathrm{MoO}_{2}$ and $\mathrm{MoO}_{3}$. This material therefore exhibits a very high repassivation potential, approaching the potential required for $\mathrm{O}_{2}$ evolution [6]. The repassivation potential is believed to be the threshold for initiation of LC [6]. In experiments with simulated crevice solutions (10 wt. $\% \mathrm{FeCl}_{3}$ ), very low (passive) corrosion rates are observed [7,8]. Finally, no significant localized attack of Alloy 22 was observed in crevices exposed to simulated acidified water (SAW) for one year. In essence, the SAW medium 
is about one-thousand times more concentrated than the ground water at Yucca Mountain (J-13 well water) and has been acidified to a $\mathrm{pH}$ of approximately 2.7. These tests were conducted in the Long Term Corrosion Test Facility (LTCTF) at Lawrence Livermore National Laboratory (LLNL) [9]. However, we have now observed the crevice corrosion of Alloy 22 during anodic polarization at very high potentials (1.2 V vs. SCE) and ambient temperature in electrolytes saturated with chloride salts, as reported here.

A variety of research is being conducted at LLNL, directed towards possible degradation modes of Alloy 22. Corrosion modeling for Total System Performance Assessment (TSPA) is a key component of this work. Models include simple correlations of experimental data [9], as well as detailed mechanistic models necessary for believable long-term predictions [4-5]. Several interactive modes of corrosion are possible and have made it necessary to develop several models that ultimately should be integrated. These process-level models include those to account for the inhibition of corrosion by protective ceramic coatings, $\mathrm{pH}$ decreases and $\mathrm{Cl}^{-}$increases in crevices, pit initiation and propagation, as well as stress corrosion and hydrogen-induced cracking. Ceramic coatings are now being considered for both corrosion allowance and corrosion resistant materials. This publication addresses the development of models to account for corrosion of Alloy 22 surfaces exposed directly to the exacerbated conditions in crevices.

\section{CREVICE CORROSION}

As discussed by Sedriks [10], $\mathrm{pH}<2$ has been observed in crevices made of stainless steel [11]. The local crevice environments for Alloy 22 and other relevant materials are being determined experimentally. Thus far, crevices have been constructed from square metallic samples, 2 inches on each side and 1/8 inch thick. The samples are masked with plastic tape, thereby forming an exposed square area, 1.7 inches on each side. The exposed area is placed underneath a clear plastic window with an access port for a $\mathrm{pH}$ sensor in the center. In this case, the sensor is miniature reference electrode separated from the crevice solution with a thin glass membrane. A second $\mathrm{pH}$ sensor is located at the mouth of the crevice, in close proximity to a saturated calomel reference electrode (SCE). The use of in situ sensors to determine crevice $\mathrm{pH}$ has also been described by Sridhar and Dunn [12]. In parallel experiments, paper strips with a pHsensitive dye ( $\mathrm{pH}$ paper) is sandwiched between the clear plastic window and photographed with a digital electronic camera in a time-lapse mode. Spectroscopic-grade graphite counter electrodes are also placed in the electrolyte lying outside the mouth of the crevice. A potentiostat is then used to control the electrochemical potential at the mouth of the crevice. Temperature, potential, current, and $\mathrm{pH}$ is then recorded electronically during the course of the experiment. Measurements of $\mathrm{pH}$ inside a Type 304 stainless steel crevice are shown in Figure 1. The electrochemical potential at the mouth was maintained at $0.8 \mathrm{~V}$ vs. SCE. Crevice corrosion could be seen initiating near the crevice mouth and propagating towards the $\mathrm{pH}$ sensor, which was located about 1 inch inside the crevice mouth. After about 3 hours, the corrosion front finally reached the $\mathrm{pH}$ sensor and the $\mathrm{pH}$ dropped from an initial value of about 5.7 to approximately 1.4 over the course of 4 to 5 hours. After about 1 hour, the fixed volume of electrolyte outside of the crevice became alkaline, reaching a fluctuating level between 10 and 12. The increase in $\mathrm{pH}$ may be due to the reduction of oxygen, which generates hydroxyl ions, accompanied by the simultaneous accumulation of dissolved metal cations, which would maintain electroneutrality. Active corrosion inside the crevice was evident since the emerald green $\mathrm{NiCl}_{2}$ solution was easily visible. In experiments with $\mathrm{pH}$ papers, the propagating corrosion front was accompanied by immediate 
acidification. After polarization of the working electrode (304 stainless steel), the indicator near the crevice mouth turned red immediately (indicative of a $\mathrm{pH}$ between 1 and 2), with the red color spreading across the paper towards the center of the sample. Before complete acidification in the entire crevice, the nucleation of pits beneath the $\mathrm{pH}$ paper was easily visible as bright red dots. Clearly, the nucleated pits were serving as local sources of acid, thereby causing localized color changes in the paper. A reference indicator outside of the crevice was photographed simultaneously to serve as a reference for the color changes observed inside the crevice. Typically, the indicator outside of the crevice would turn green $(8<\mathrm{pH}<10)$. Similar experiments were performed with Alloy 22. In this case, the working electrode (Alloy 22) remained passive at all locations inside the crevice. There was no visible evidence of localized corrosion of the metal surface underneath the clear plastic window, and no bright red dots appeared underneath the indicator paper. Even though the crevice remained passive, the passive current density and imposed electric field within the crevice was sufficient to cause significant acidification. Here too the $\mathrm{pH}$ dropped relatively low levels $(1<\mathrm{pH}<2)$. Additional experimental work is now being conducted and will facilitate further develolpment of predictive models.

A detailed deterministic model has been developed to calculate the spatial distributions of electrochemical potential and current density in crevices, as well as transient concentration profiles of dissolved metals and ions [4,5]. It is assumed that the local concentration of hydrogen ions is limited by either (a) anion transport or (b) the rate of hydrolysis. If the limitation is assumed to be due to anion transport, all hydrolysis reactions at each point inside the crevice are assumed to instantaneously reach equilibrium. Furthermore, it is assumed that electroneutrality is maintained at each point. In contrast, if the limitation is assumed to be hydrogen ion production and transport, the local generation rate of hydrogen ion must be known and is assumed to be proportional to the dissolution rates of dissolved metals, with proportionality constants being calculable from hydrolysis equilibrium constants. Note that rate constants for the hydrolysis reactions are unknown, with experimental determination being impractical. In this case, anion concentrations are calculated at each point based upon electroneutrality. This model can be used to estimate the extent of $\mathrm{pH}$ decreases in crevices due to the simultaneous hydrolysis and transport of dissolved $\mathrm{Fe}, \mathrm{Ni}, \mathrm{Cr}, \mathrm{Mo}$ and $\mathrm{W}$. At the present time, dissolved metal species included in the calculation are $\mathrm{Fe}^{2+}, \mathrm{Fe}(\mathrm{OH})^{+}, \mathrm{Fe}^{3+}, \mathrm{Fe}(\mathrm{OH})^{2+}, \mathrm{Ni}^{2+}, \mathrm{Ni}(\mathrm{OH})^{+}, \mathrm{Cr}^{3+}, \mathrm{Cr}(\mathrm{OH})^{2+}, \mathrm{Cr}(\mathrm{OH})_{2}{ }^{+}, \mathrm{Mo}^{3+}$ and $\mathrm{WO}_{4}^{2-}$. Possible precipitates include $\mathrm{Fe}(\mathrm{OH})_{2}, \mathrm{Ni}(\mathrm{OH})_{2}, \mathrm{Cr}(\mathrm{OH})_{3}, \mathrm{MoO}_{2}$ and $\mathrm{WO}_{3}$. The solubilities of various oxides and hydroxides believed to be formed during dissolution of Alloy 22 are given by Pourbaix [13]. A limitation of the current analysis is the lack of consideration of various $\mathrm{Cl}^{-}$complexes (i.e. $\mathrm{NiCl}_{2}, \mathrm{FeCl}^{+}$, etc.) and the assumption that all ions have similar diffusion coefficients.

The specific calculations shown here assume: (1) $25^{\circ} \mathrm{C}$; (2) $170,000 \mathrm{ppm}$ or $2.9 \mathrm{M} \mathrm{NaCl}$; (3) $0.5882 \mu \mathrm{S} \mathrm{cm}^{-1}$ per ppm NaCl; (3) a diffusion coefficient of $1.9 \times 10^{-5} \mathrm{~cm}^{2} \mathrm{sec}^{-1}$ for all dissolved species; and (4) an initial crevice width is $0.015 \mathrm{~cm}$. In the case of Type 304 stainless steel, it was assumed that: (1) the potential at the mouth of the crevice is at $0.400 \mathrm{~V}$ vs. SCE; (2) the corrosion potential and current density are $-0.400 \mathrm{~V}$ vs. SCE and $1.0 \times 10^{-7} \mathrm{~A} \mathrm{~cm}^{-2}$, respectively; (3) the passive region extends from -0.350 to $0.350 \mathrm{~V}$ vs. SCE and is characterized by a passive current density of $5.0 \times 10^{-6} \mathrm{~A} \mathrm{~cm}^{-2}$; (4) the threshold potential for breakdown of the passive film is $0.350 \mathrm{~V}$ vs. SCE; and (5) the current density due to localized corrosion is $1.0 \times 10^{-3}$ at $0.400 \mathrm{~V}$ vs. SCE. In the case of Alloy 22, it was assumed that: (1) the potential at the mouth of the crevice is at 0.800 $\mathrm{V}$ vs. SCE; (2) the corrosion potential and current are $-0.160 \mathrm{~V}$ vs. SCE and $2.0 \times 10^{-8} \mathrm{~A} \mathrm{~cm}^{-2}$, 
respectively; (3) the passive region extends from -0.100 to $0.700 \mathrm{~V}$ vs. SCE and is characterized by a passive current density of $2.0 \times 10^{-6} \mathrm{~A} \mathrm{~cm}^{-2}$; (4) the threshold potential for breakdown of the passive film is $0.700 \mathrm{~V}$ vs. SCE; and (5) the current density due to localized corrosion is $1.0 \times 10^{-2}$ at $0.850 \mathrm{~V}$ vs. SCE.

Calculations for crevice corrosion of Type 304 stainless steel are discussed first. Since the electrochemical potential (E) was predicted to decrease with increasing crevice depth, it is expected that the potential should never be more severe (closer to the threshold for LC) than at the crevice mouth. Figure 2 shows calculated values of $\mathrm{pH}$ and ion concentration as a function of distance from the crevice mouth. Calculations are at 600 -second intervals, with the last calculated value at 3600 seconds. Values of $\mathrm{pH}$ estimated by Method 1 (limited by hydrolysis) and Method 2 (limited by anion transport) are both shown. Based upon Method 2, it is concluded that the pH could be 1.5 to 2.0 in a crevice that is predominately in the passive region. This general conclusion is now supported by measurements of crevice $\mathrm{pH}$, which are found to be less than two $(\mathrm{pH}<2)$. These early tests were done with saturated $\mathrm{KCl}$. As computational and experimental techniques improve, exact comparisons between predictions and measurement should be possible. Simulations at higher anodic potential involve larger current densities, larger rates, and much smaller increments in time and space.

Calculations for crevice corrosion of Alloy 22 are discussed here and illustrated in Figures 3 through 6. Figure 3 shows calculated values of $\mathrm{pH}$ and ion concentration as a function of distance from the crevice mouth. Calculations are at 600 second intcrvals, with the last calculated value at 3600 seconds. Values of $\mathrm{pH}$ estimated by Method 1 (limited by hydrolysis) and Method 2 (limited by anion transport) are both shown. Based upon Method 2, it is concluded that the pH could be 1.5 to 2.0 in a crevice that is essentially passive. This general conclusion is now supported by measurements of $\mathrm{pH}$ in a passive crevice formed from Alloy 22, which was found to be less than two $(\mathrm{pH}<2)$. These early tests were done with saturated $\mathrm{KCl}$. Transients in the total concentrations of dissolved Fe, Ni, Cr, Mo and W at 0, 600, 1200, 1800, 2400, 3000 and 3600 seconds are shown in Figure 4. With the exception of tungsten, these concentrations rise sharply from zero at the crevice mouth to constant values (a plateau) deep inside the crevice. Recall that the concentrations are assumed to be zero at the crevice mouth. Figure 5 shows the distributions of dissolved $\mathrm{W}$, which is assumed to be $\mathrm{WO}_{4}{ }^{2-}$, and precipitated $\mathrm{WO}_{3}$ inside the crevice. This unusual behavior is due to the retrograde dependence of tungsten solubility on pH (less soluble in acidic environments) [13]. At positions in the crevice with low $\mathrm{pH}$, the corrosion of Alloy 22 results in the formation of solid $\mathrm{WO}_{3}$. Near the crevice mouth, which has a higher $\mathrm{pH}$, the tungsten begins to dissolve. The penetration and oxide growth rates inside the crevice are shown in Figure 6. Since the dissolution rate of the Alloy 22 wall is governed by the passive current density at all points inside the crevice, the predicted pentration rate is the same at all locations, despite differences spatial variations in electrochemical potential, $\mathrm{pH}$ and metal ion concentration. In the case of an ideal polarization curve, the current density is independent of electrochemical potential. The model calculates the potential and current distribution in the crevice. However, the limited length of this paper prevents the inclusion of those portions of the calculation here. The model is capable of accounting for the dependence of the passive current density on $\mathrm{pH}, \mathrm{Cl}$-, and temperature. However, such dependence has not been accounted for here. 


\section{SUMMARY}

Crevices formed with Alloy 22 will lead to a localized environment with decreased $\mathrm{pH}$ and increased chloride, even in cases where the passive film remains stable. However, the electrochemical potential inside the crevice is expected to be well below that at the mouth, which will probably be well below the repassivation potential. Therefore, catastrophic localized breakdown of the passive film inside the crevice is not expected. This is consistent with atomic force microscopy (AFM) of surfaces inside such crevices [5]. These conditions are expected to maintain a passive corrosion rate inside the crevice. It is predicted that the corrosion product remaining on the Alloy 22 surface is enriched in tungsten. The model described here is capable of accounting for the effect of crevice gap on decreases in $\mathrm{pH}$. In general, such transport models predict lower $\mathrm{pH}$ as the crevice gap becomes smaller. More work is required to determine whether or not such reductions in $\mathrm{pH}$ can cause conditions that might lead to a loss of passivity at high temperature $\left(90-95^{\circ} \mathrm{C}\right)$. Such parametric studies have been reported elsewhere [5], but require additional refinement and validation.

\section{ACKNOWLEDGEMENTS}

This work was done under the auspices of the U.S. Department of Energy (DOE) by Lawrence Livermore National Laboratory (LLNL) under Contract No. W-7405-Eng-48.

\section{REFERENCES}

1. J. W. Oldfield, W. H. Sutton, Brit. Corr. J. 13 (1), 13-22 (1978).

2. E. A. Nystrom, J. B. Lee, A. A. Sagues, H. W. Pickering, J. Electrochem. Soc. 141 (2), 358361 (1994).

3. J. C. Walton, G. Cragnolino, S. K. Kalandros, Corr. Sci. 38 (1), 1996, 1-18 (1996).

4. J. C. Farmer, R. D. McCright, Paper No. 98160, Corrosion 98 (San Diego, CA, March 22-27, 1998, NACE, Houston, TX); UCRL-ID-127980, Parts 1 \& 2 (1997, LLNL, Livermore, CA).

5. J.C. Farmer, P. J. Bedrossian, R. Daniel McCright, Spectrum 98, Vol. 1 (Denver, CO, Sept. 13-18, 1998, ANS, La Grange Park, IL) pp. 610-623.

6. K. A. Gruss, D. S. Dunn, G. A. Cragnolino, N. Sridar, Paper No. 98149, Corrosion 98 (San Diego, CA March 22-27, 1998, NACE, Houston, TX).

7. Haynes International, Inc., Product Brochure H-2002B (1987).

8. A. I. Asphahani, Materials Performance 19 (12), 33-43 (1980).

9. J. C. Farmer, ICONE-6 (San Diego, CA, May 10-15, 1998, ASME).

10. A. J. Sedriks, Corrosion of Stainless Steels, $2^{\text {nd }}$ ed. (Wiley, New York, NY, 1996) p. 179.

11. F. D. Bogar, C. T. Fujii, NRL Report 7690 (Naval Research Laboratory, 1974).

12. N. Sridhar, D. S. Dunn, Corrosion, 50 (11), 857-872 (1994).

13. M. Pourbaix, Atlas of Electrochemical Equilibria in Aqueous Solutions, English Translation, J. A. Franklin (Pergamon Press, New York, NY; Cebelcor, Brussels, Belgium, 1966) p. 644. 


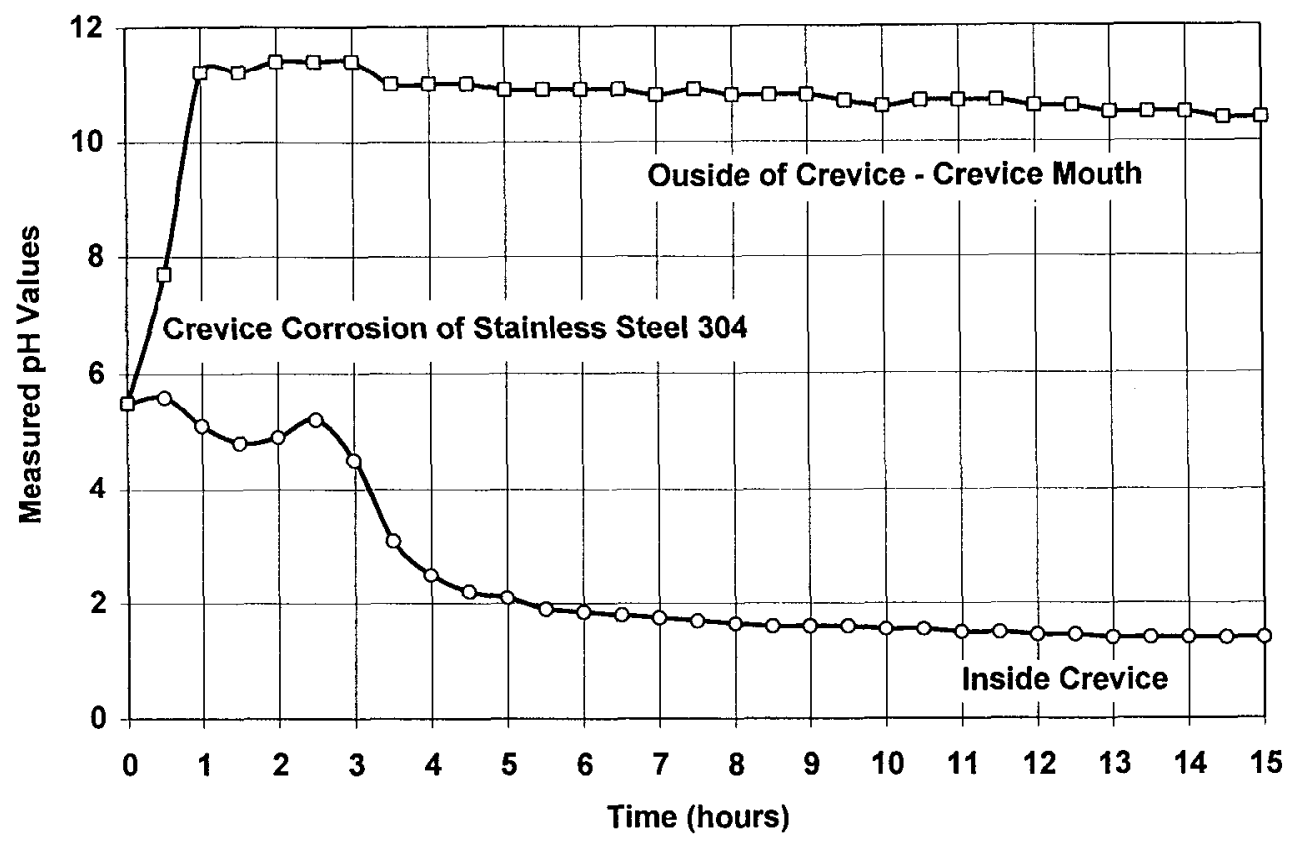

Figure 1. Measured $\mathrm{pH}$ during crevice corrosion of 304 stainless steel in saturated $\mathrm{KCl}$ at $25^{\circ} \mathrm{C}$ with applied potential of $0.8 \mathrm{~V}$ vs. SCE. Measured values confirmed with indicator.

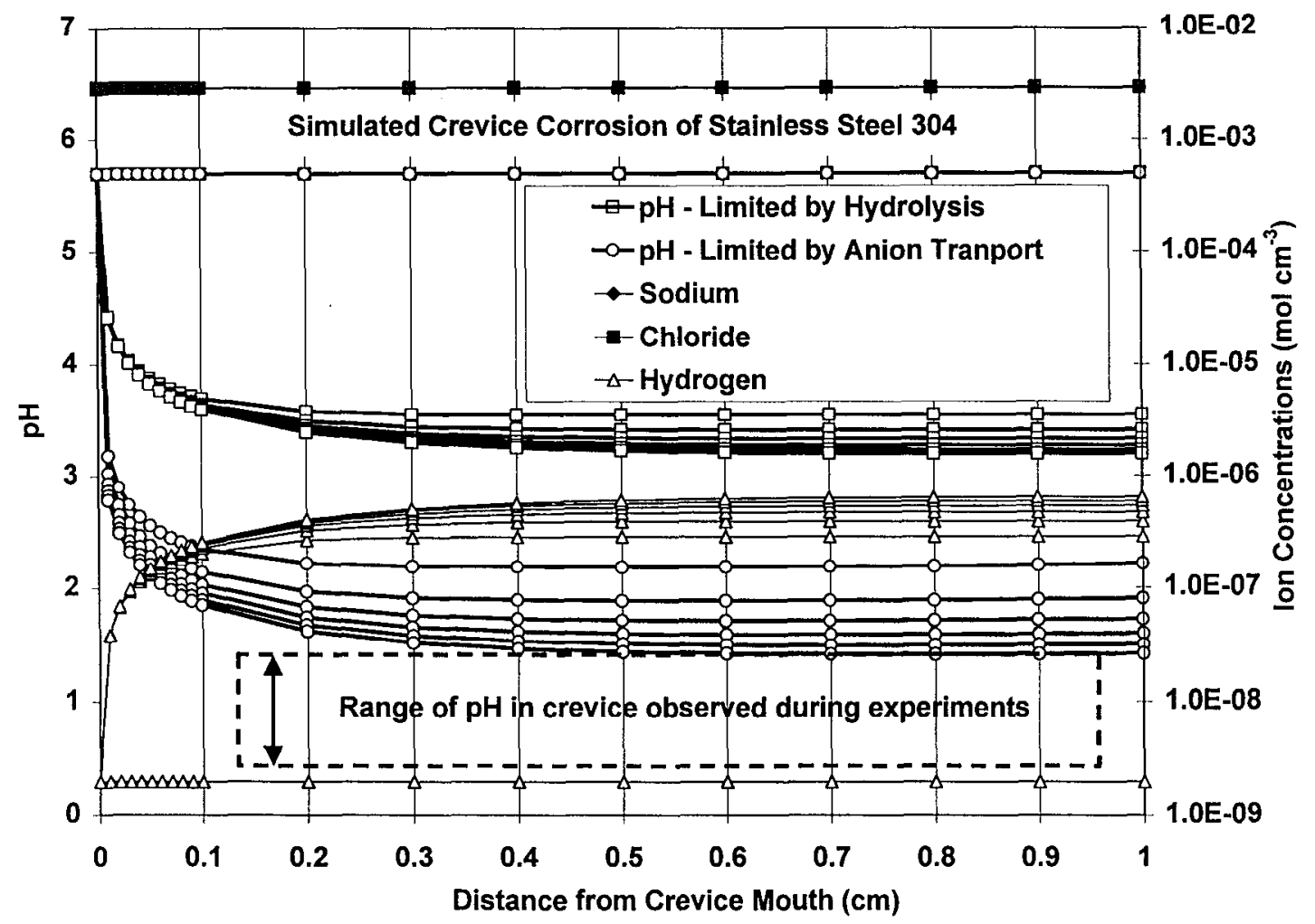

Figure 2. Simulated crevice corrosion of Type 304 stainless steel in saturated $\mathrm{NaCl}$ at $25^{\circ} \mathrm{C}$ with applied potential of $0.4 \mathrm{~V}$ vs. SCE. Predicted $\mathrm{pH}$ profiles at 600 -second increments with lowest predicted levels at 3600 seconds. 


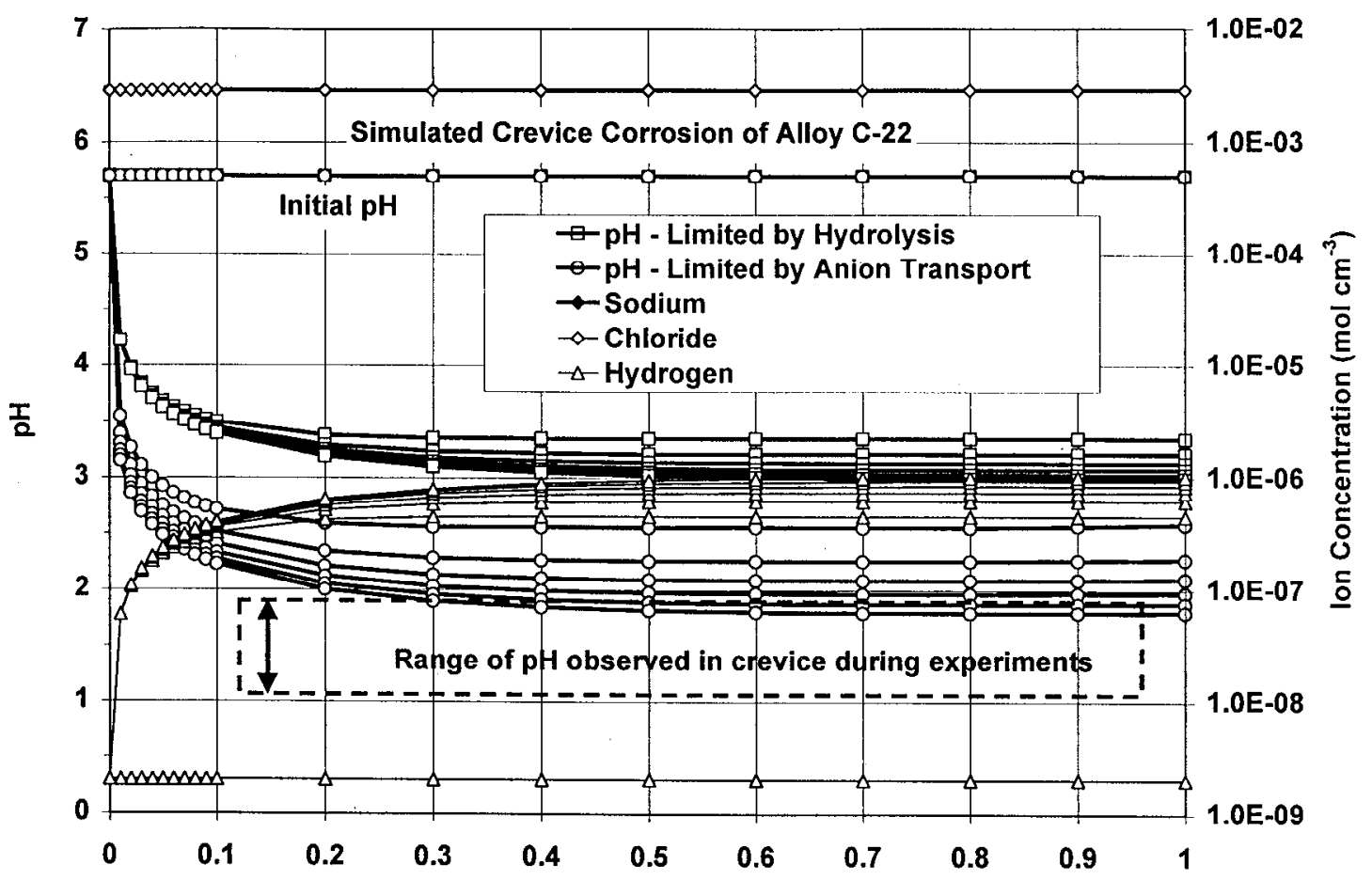

Distance from Crevice Mouth (cm)

Figure 3. Simulated crevice corrosion of Alloy 22 in saturated $\mathrm{NaCl}$ at $25^{\circ} \mathrm{C}$ with applied potential of $0.8 \mathrm{~V}$ vs. SCE. Predicted pH profiles at 600 -second increments with lowest predicted levels at 3600 seconds.

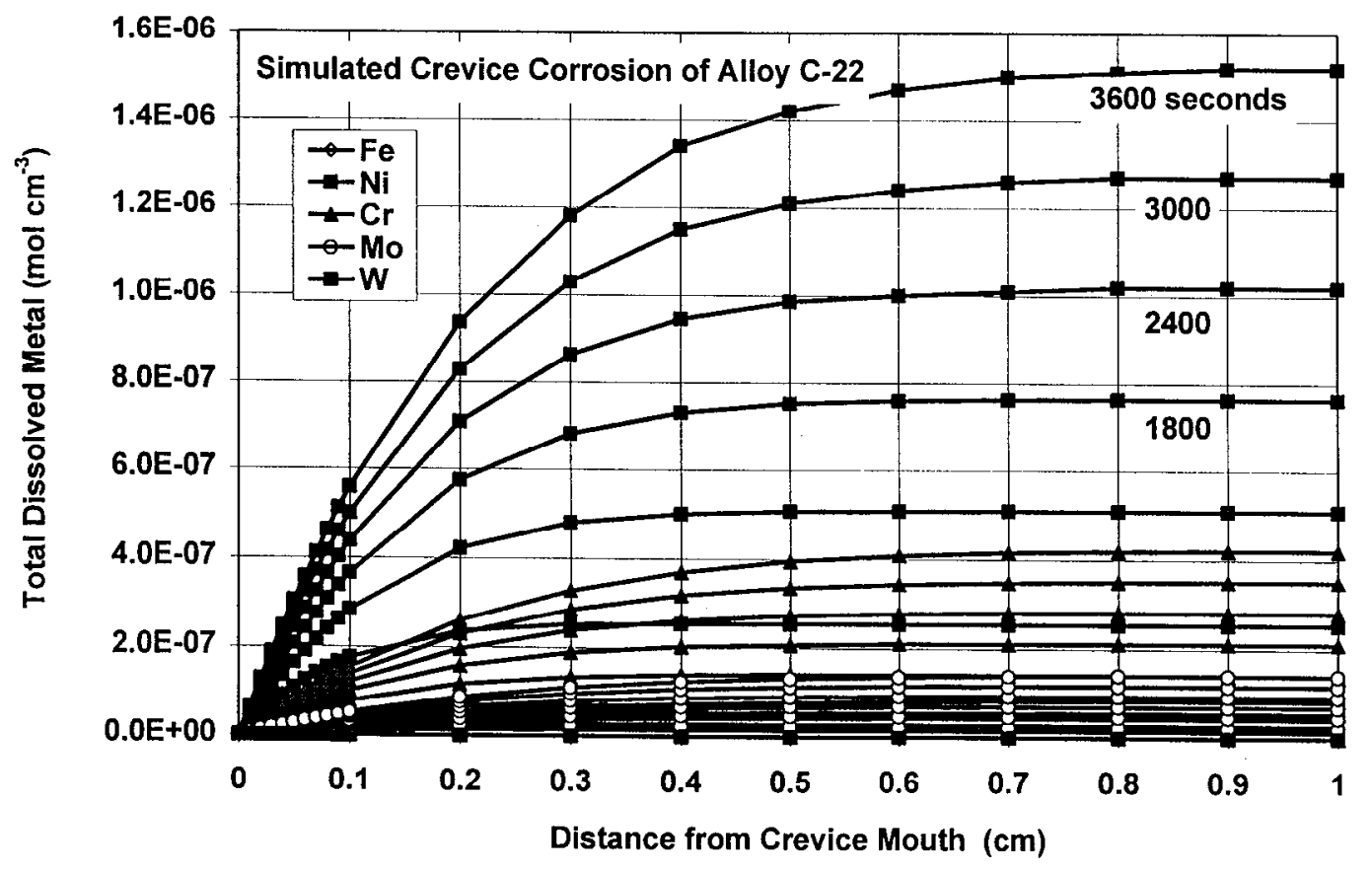

Figure 4. Simulated crevice corrosion of Alloy 22 in saturated $\mathrm{NaCl}$ at $25^{\circ} \mathrm{C}$ with applied potential of $0.8 \mathrm{~V}$ vs. SCE. Predicted dissolved metal profiles at 600 second intervals with the highest values at 3600 seconds. Corresponds to Figure 3. 


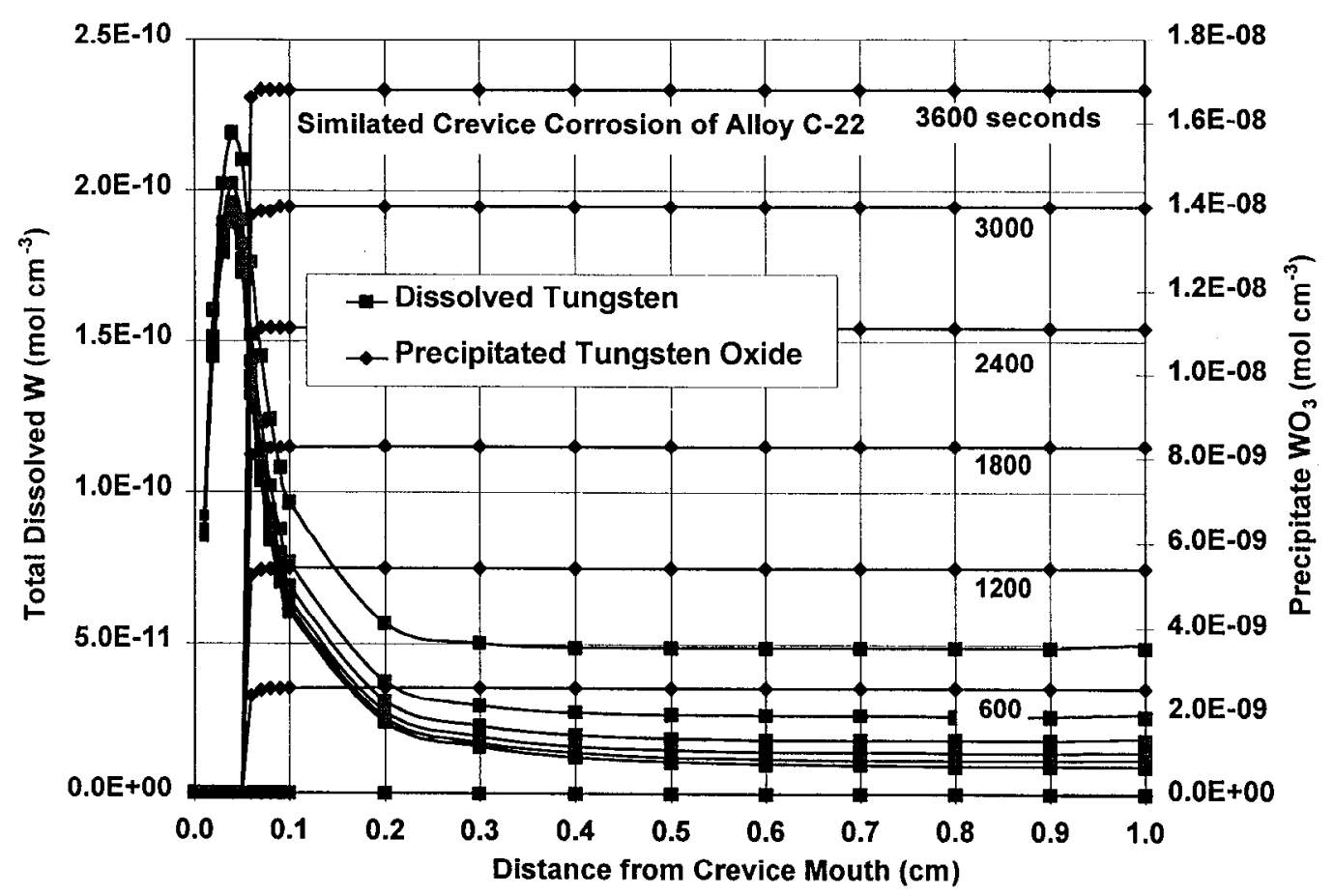

Figure 5. Simulated crevice corrosion of Alloy 22 in saturated $\mathrm{NaCl}$ at $25^{\circ} \mathrm{C}$ with applied potential of $0.8 \mathrm{~V}$ vs. SCE. Predicted profiles for dissolved $\mathrm{W}$ and precipitated $\mathrm{WO}_{4}$ at 600 second intervals with the highest values at 3600 seconds. Corresponds to Figurc 3.

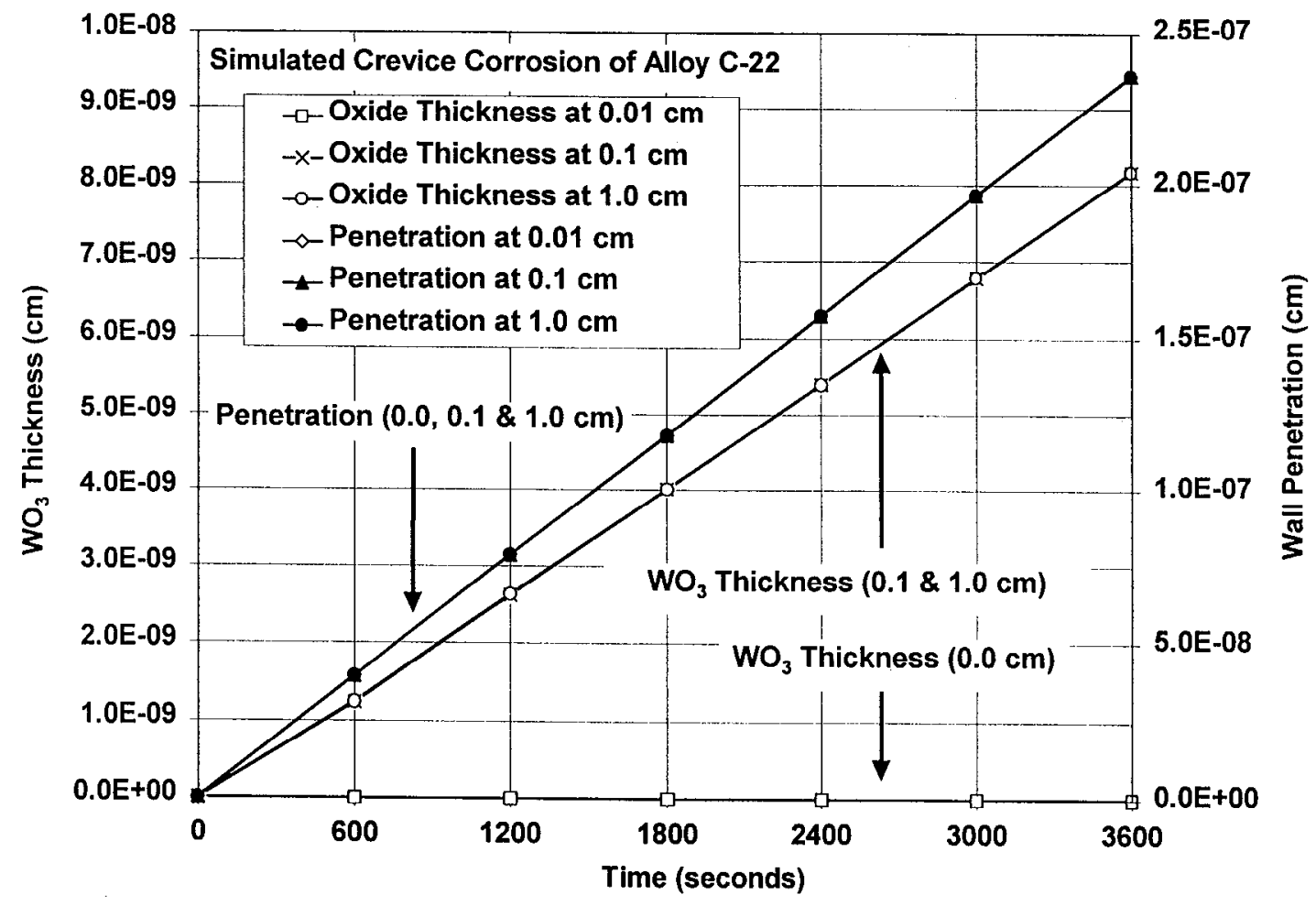

Figure 6. Simulated crevice corrosion of Alloy 22 in saturated $\mathrm{NaCl}$ at $25^{\circ} \mathrm{C}$ with applied potential of $0.8 \mathrm{~V}$ vs. SCE. Predicted wall penetration and $\mathrm{WO}_{3}$ thickness at $0.01,0.1$ and 1.0 $\mathrm{cm}$ from the crevice mouth. Corresponds to Figure 3. 